\title{
AVALIAÇÃO DA CORROSÃO INTERGRANULAR NO AÇO AISI 304L PELA NORMA ASTM A262, PRÁTICAS A, C E E*
}

Luana Araújo Batista ${ }^{1}$ Tarcísio Reis de Oliveira ${ }^{2}$

\section{Resumo}

Os aços inoxidáveis austeníticos apresentam interessante junção de propriedade mecânica com elevada resistência à corrosão. Porém, quando aplicados em temperaturas na faixa de sensitização e submetidos a ambientes agressivos, tornam-se suscetíveis à corrosão intergranular. Para verificação da suscetibilidade desses aços sofrem este fenômeno são realizados ensaios de corrosão. Dentre eles os mais utilizados são os contidos na norma ASTM A262, que possui cinco diferentes procedimentos. Este trabalho consiste na comparação dos procedimentos das Práticas A, C e E, contidos nessa norma, para determinação da tendência à corrosão intergranular do aço AISI 304L. Para isto, amostras do aço foram sensitizadas a $675^{\circ} \mathrm{C}$ por uma hora e em seguida submetidas aos diferentes ensaios descritos na norma. Após a realização dos três procedimentos, considera-se que a metodologia mais assertiva e confiável seja a Prática E, conhecido como ensaio de Strauss, e que as amostras analisadas não apresentaram corrosão intergranular.

Palavras-chave: AISI 304L; Corrosão intergranular; ASTM A262.

\section{EVALUATION OF INTERGRANULAR CORROSION ON STEEL AISI 304L BY METHOD ASTM A262, PRACTICE A, C AND E}

\section{Abstract}

The austenitic stainless steels have interesting junction mechanical property with high corrosion resistance. However, when applied at temperatures in the range of sensitization and subjected to harsh environments, they become susceptible to intergranular corrosion. To verify the susceptibility of these steels suffer from this phenomenon corrosion tests are performed. Among them the most used are those contained in ASTM A262, which has five different procedures. This work consists in comparing the procedures of Practices $A, C$ and $E$ contained in this standard for determining the tendency to intergranular corrosion of steel AISI 304L. For this, the steel samples were sensitizadas at $675^{\circ} \mathrm{C}$ for one hour and then subjected to the various tests described in the standard. After completion of the three procedures, it is considered that the most assertive and reliable methodology is the Practice $\mathrm{E}$, known as Strauss test, and the samples analyzed showed no intergranular corrosion.

Keywords: AISI 304L; Intergranular corrosion; ASTM A262.

1 Graduanda em Engenharia Metalúrgica, Centro Universitário do Leste de Minas Gerais - Unileste, Associada ABM Júnior, Coronel Fabriciano, Minas Gerais, Brasil.

2 Engenheiro Mecânico, Doutor em Engenharia Metalúrgica, Pesquisador, Centro de Pesquisas, Aperam South America, Timóteo, MG, Brasil. 


\section{INTRODUÇÃO}

Os aços inoxidáveis austeníticos são conhecidos por suas boas propriedades mecânicas e elevada resistência à corrosão. Sendo os principais os da série 300 , dos quais o fundamental deles é o 304, conhecido internacionalmente como AISI $304(18 \% \mathrm{Cr}$ e $8 \% \mathrm{Ni})$ com teor de carbono máximo de $0,08 \%$. Por conter teor de carbono consideravelmente alto, o aço AISI 304 é suscetível à corrosão intergranular pelo empobrecimento em cromo das regiões adjacentes ao contorno de grão, devido à precipitação de carbonetos de cromo.

Esta precipitação de carbonetos de cromo ocorre quando o aço austenítico é tratado termicamente e submetido a temperaturas na faixa de 400 a $850^{\circ} \mathrm{C}$. Nesta faixa de temperatura, o cromo e o carbono se combinam e formam o carboneto de cromo $\left(\mathrm{Cr}_{23} \mathrm{C}_{6}\right)$. Ao se precipitarem, os carbonetos empobrecem a região vizinha em cromo, fazendo com que estas regiões descromizadas deixem de ser inoxidáveis. Fenômeno este que é denominado de sensitização.

Com a sensitização, o aço se torna menos resistente ao ataque de certos meios agressivos e como consequência sofre um ataque localizado na região descromizada no entorno do contorno de grão, gerando a corrosão intergranular também conhecida como valetamento.

Padilha [1] cita em seu livro que, entre as maneiras de se evitar a sensitização estão o uso de aços com menor teor de carbono, aços estabilizados com adição de titânio ou nióbio e para casos de materiais soldados a aplicação de um tratamento térmico de solubilização com resfriamento rápido. Dentre estas opções a mais utilizada é a aplicação de aços com baixo teor de carbono denominados de Low Carbon. Deste conceito surgiu o AISI 304L, que possui teor de carbono máximo de 0,03\%.

Para quantidades de carbono inferiores a $0,03 \%$, o carbono permanece em solução sólida na matriz do aço e o pouco que permanece livre precipita-se na forma de $\mathrm{Cr}_{23} \mathrm{C}_{6}$ em quantidades insuficientes para prejudicar a resistência à corrosão, aumentando assim, a resistência à corrosão intergranular deste aço.

No entanto, é mencionado no ASM Speciality Handbook [2], que o AISI 304L foi desenvolvido para rápidas exposições na faixa de temperatura de sensitização, como no processo de soldagem, mas que em longas exposições nesta faixa de temperatura crítica, este aço também sofrerá sensitização. Ou seja, ele não é um aço completamente imune a sensitização.

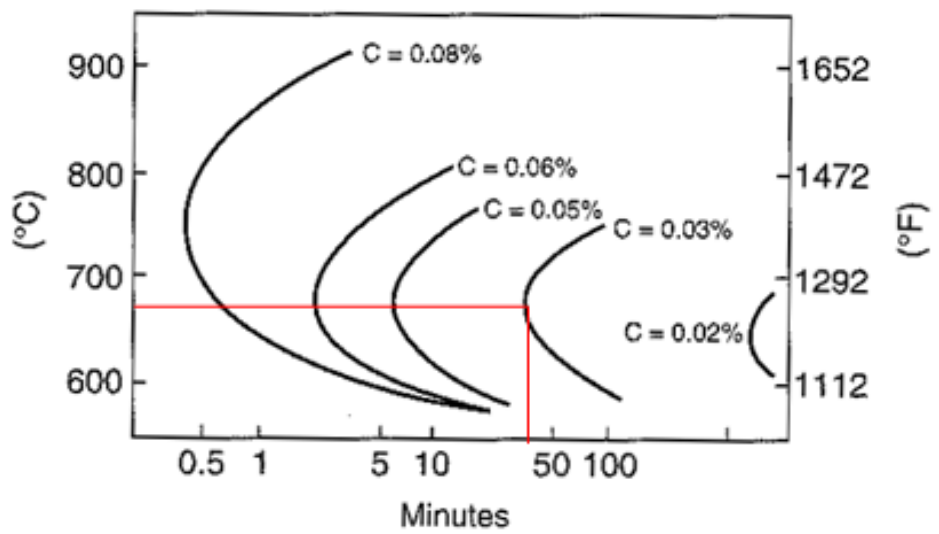

Figura 1. Curvas de precipitação de carbonetos em função do tempo, temperatura e teor de carbono do aço [2]. 
Pode-se observar que um aço com teor de carbono de $0,030 \%$ à $675^{\circ} \mathrm{C}$ precipitará carbonetos antes de 50 minutos de exposição. E que a resistência à sensitização em aços com teor de carbono igual ou inferior a $0,020 \%$ é muito maior do que a de um aço com $0,030 \%$ de carbono. O que comprova a influência do teor de carbono na precipitação de carbonetos de cromo.

Para verificação da tendência do aço AISI 304L sofrer o fenômeno de sensitização durante a aplicação final do aço, são realizados ensaios de corrosão no material. $O$ ensaio mais utilizado pelas indústrias consiste no procedimento da norma ASTM A262 - Prática A. No entanto, como na própria norma é citado, os resultados obtidos neste procedimento não são determinantes para a rejeição do material e outras metodologias são apresentadas na ASTM A262 [3].

Este trabalho tem por objetivo verificar a suscetibilidade à corrosão intergranular do aço inoxidável austenítico AISI 304L na condição de solubilizado e sensitizado à $675^{\circ} \mathrm{C}$ por 1 hora, de acordo com a norma ASTM A262 práticas A, C e E. A fim de determinar-se o melhor procedimento desta norma para avaliação da corrosão intergranular.

\section{MATERIAIS E MÉTODOS}

Utilizadas amostras do aço AISI 304L solubilizado, cedidas pela Aperam South America, planta de Timóteo, em espessuras variadas entre 1,30 a 3,00 mm. Todas as amostras utilizadas nos testes de corrosão foram previamente sensitizadas a $675^{\circ} \mathrm{C}$ por 1 hora.

A norma ASTM A262 Prática A corresponde a um teste eletroquímico com ataque de ácido oxálico a $10 \%$ com corrente de $1 \mathrm{~A} / \mathrm{cm}^{2}$, visando à classificação da estrutura do material por meio da análise da corrosão devido à sensitização de aços inoxidáveis com baixo teor de carbono. Segundo a descrição desta metodologia, a estrutura do material pode ser classificada basicamente como degrau, mista ou valetada. $\mathrm{Na}$ estrutura degrau existem desníveis entre os grãos, mas não há precipitados de cromo nos contornos de grão. A estrutura mista apresenta carbonetos de cromo precipitados nos contornos de grão e com ataque excessivo em partes do contorno, mas não apresenta nenhum grão em que seu contorno tenha sido totalmente corroído. Se houver a precipitação de carbonetos, e consequentemente, a corrosão de todo o contorno de pelo menos um único grão, em que o ataque do contorno esteja totalmente definido com estrutura fechada, esta microestrutura será classificada como valetada. Para este ensaio, amostras do aço foram cortadas na dimensão de $100 \times 200 \mathrm{~mm}$. Após ataque, as análises foram efetuadas em microscópio ótico com ampliações de 500 vezes.

Uma vez que a Prática $A$ não é determinante para a rejeição do material, foram realizados ensaios conforme a Prática C da ASTM A262. Previamente à realização deste ensaio, as amostras solubilizadas foram lixadas para remoção de toda a superfície oxidada das amostras para que não ocorresse ataque preferencial em áreas mais susceptíveis durante o ensaio.

O procedimento da Prática $\mathrm{C}$ consiste em um teste de corrosão com a amostra em imersão em ácido nítrico a $65 \%$ em ebulição por ciclos de 48 horas, podendo ser estendido a até cinco ciclos. Cada ciclo serve para extrapolar a taxa de corrosão equivalente a um mês de exposição do material em ambientes agressivos. Foram realizados três ciclos e calculadas as taxas de corrosão a partir da diminuição do peso das amostras. Após o terceiro ciclo as superfícies das amostras foram 
analisadas em microscópio eletrônico de varredura (MEV). As dimensões das amostras para este ensaio podem ser observadas na Tabela 1.

Tabela 1. Dados das amostras do aço AISI 304L para o teste de corrosão segundo a ASTM A262 Prática C

\begin{tabular}{cccccccc}
\hline Amostra & $\begin{array}{c}\text { Massa in. } \\
\boldsymbol{g}\end{array}$ & $\begin{array}{c}\text { Comp. } \\
\mathbf{c m}\end{array}$ & $\begin{array}{c}\text { Largura } \\
\mathbf{c m}\end{array}$ & $\begin{array}{c}\text { Área } \\
\mathbf{c m}^{\mathbf{2}}\end{array}$ & $\begin{array}{c}\text { Espes. } \\
\mathbf{c m}\end{array}$ & $\begin{array}{c}\text { Volume } \\
\mathbf{c m}^{\mathbf{3}}\end{array}$ & $\begin{array}{c}\text { Densidade } \\
\mathbf{g} / \mathbf{c m}^{\mathbf{3}}\end{array}$ \\
\hline 1 & 14,931 & 3,948 & 3,649 & 14,406 & 0,133 & 1,923 & 7,763 \\
\hline 2 & 32,383 & 3,955 & 3,814 & 15,084 & 0,274 & 4,1289 & 7,843 \\
\hline 3 & 16,352 & 4,003 & 3,920 & 15,692 & 0,133 & 2,084 & 7,847 \\
\hline 4 & 15,711 & 3,904 & 3,897 & 15,214 & 0,132 & 2,011 & 7,811 \\
\hline 5 & 38,159 & 3,999 & 3,997 & 15,984 & 0,305 & 4,878 & 7,822 \\
\hline 6 & 36,859 & 3,999 & 3,868 & 15,468 & 0,304 & 4,702 & 7,838 \\
\hline
\end{tabular}

A terceira metodologia utilizada, Prática E da ASTM A262, conhecida como Ensaio de Strauss, consiste em imergir amostras previamente solubilizadas em solução de ácido sulfúrico com sulfato de cobre durante um tempo mínimo 15 horas e, depois de lavadas e secas, submetê-las ao ensaio de dobramento. Se a amostra fraturar durante o dobramento de $180^{\circ}$ o material é considerado valetado. Esta análise se torna, assim, a mais confiável por não depender da análise microestrutural do material e tampouco do julgamento do executor das análises. Quando o material está valetado a trinca é visível em escala macrométrica, para análise visual foi utilizado lupa e microscópio.

A dimensão do corpo de prova padrão para este ensaio é de $100 \times 20 \mathrm{~mm}$. No entanto, devido aos inúmeros ensaios realizados anteriormente, não se dispunha de amostras sensitizadas nestas dimensões. As amostras utilizadas continham as medidas de $50 \times 20 \mathrm{~mm}$. É importante ressaltar que estas dimensões respeitaram ao distanciamento mínimo exigido por norma, onde a espessura do cutelo deve ser igual à espessura da amostra e que a abertura entre o cutelo e o batente da máquina de dobramento deve ser de 2,5 vezes a espessura da amostra.

\section{RESULTADOS E DISCUSSÃO}

\subsection{ASTM A262 - Prática A}

As micrografias da Figura 2 foram classificadas como estrutura mista segundo a Prática A. Nestas amostras houve a precipitação de carbonetos de cromo nos contornos de grão e, subsequentemente, ataque às regiões descromizadas no entorno dos grãos. No entanto, não foi observado ataque total dos contornos, onde nenhum grão foi totalmente fechado. Pela norma, apenas quando se tem precipitação e ataque no contorno completo de pelo menos um grão é que se pode considerar a microestrutura valetada. 


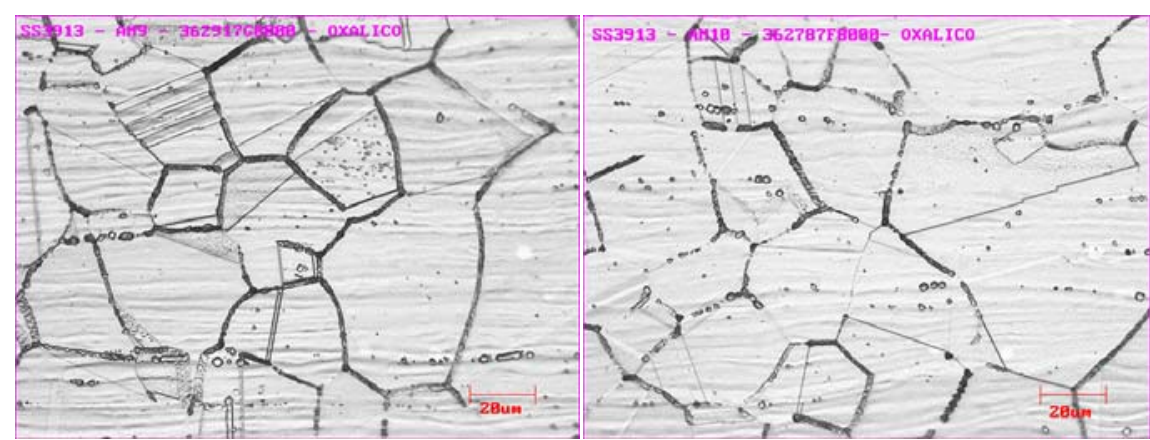

Figura 2. Estruturas do aço AISI 304L classificadas como mistas segundo ASTM A262 Prática A. Ampliação de 500x.

Em algumas amostras houve a dificuldade quanto à classificação da estrutura como mista ou valetada, uma vez que, as imagens não se enquadravam nos exemplos da ASTM A262 - Prática A. Como pode ser observado na Figura 3, nas amostras o ataque aos contornos de grãos foi em menor intensidade, comparado ao exemplo da norma, e os contornos mais rodeados apresentam pequenas falhas que impedem o completo fechamento da estrutura.

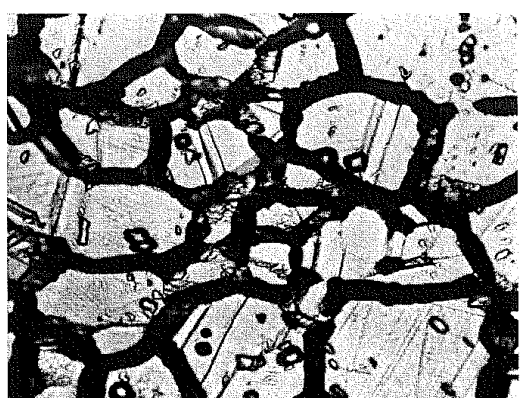

(a)

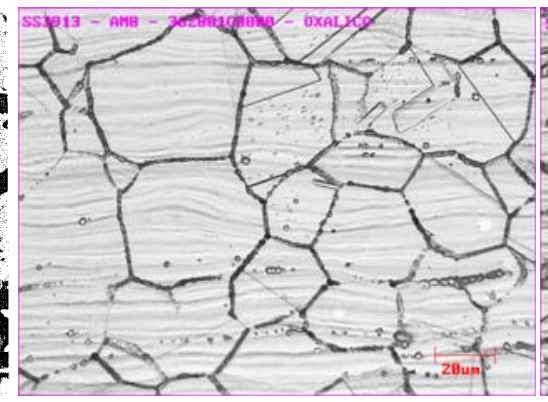

(b)

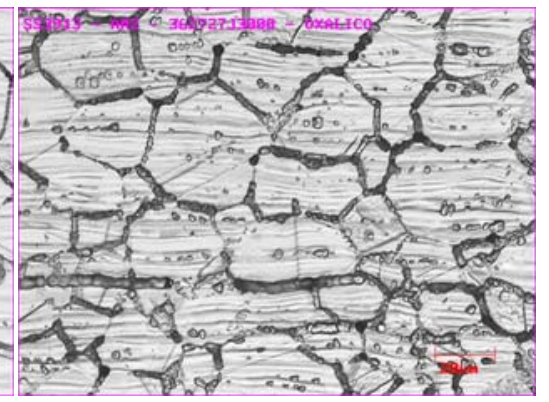

(c)

Figura 3. Estruturas do aço AISI 304L, (a) exemplo da norma ASTM A262 Prática A, (b) e (c) amostras dos autores. Ampliação de 500x.

Uma consideração a ser feita é que pela ASTM A262 não se pode condenar um material como valetado ou impróprio apenas com a análise visual da Prática A. Para validação do valetamento é necessário que seja realizado outro teste descrito na norma para classificá-lo como impróprio.

\subsection{ASTM A262 - Prática C}

Os resultados dos três ciclos de 48 horas do teste de corrosão segundo a ASTM A262 - Prática C das amostras se encontra na Tabela 2. Sedriks [4] cita em seu livro uma tabela de taxa máxima de corrosão usada pela DuPont, para a seleção de aços inoxidáveis para a utilização em reatores de plantas petroquímicas que funcionam na faixa de sensitização. Para a avaliação da taxa de corrosão das amostras, utilizou-se como referência o valor limite estipulado pela DuPont de 0,0020 polegadas por mês para o AISI 304L na condição de encharque de 1 hora à $675^{\circ} \mathrm{C}$. Salienta-se que não é estabelecido pela norma ASTM A262 um valor limite da taxa de corrosão, bem como não é determinado um tempo específico de permanência na temperatura crítica durante o tratamento térmico de sensitização prévio. Estas informações deverão ser estipuladas de acordo com as condições de trabalho do aço, ou seja, tempo de exposição a temperaturas na faixa de sensitização e agressividade do meio. 
Tabela 2. Taxa de corrosão em polegadas por mês das amostras AISI 304L submetidas à Prática C

\begin{tabular}{cccc}
\hline Amostra & Etapa 1 - 48h & Etapa 2 - 96h & Etapa 3 - 144h \\
\hline 1 & 0,00234 & 0,00314 & 0,00475 \\
\hline 2 & 0,00182 & 0,00196 & 0,00230 \\
\hline 3 & 0,00170 & 0,00244 & 0,00371 \\
\hline 4 & 0,00177 & 0,00185 & 0,00201 \\
\hline 5 & 0,00159 & 0,00197 & 0,00234 \\
\hline 6 & 0,00201 & 0,00232 & 0,00275 \\
\hline
\end{tabular}

Outra referência quanto à taxa de corrosão do AISI 304L é da empresa Sandvik [5], que apresenta a taxa de corrosão em função do tempo de sensitização em horas, Figura 4. Convertendo a taxa de corrosão limite da DuPont de 0,0020 pol/mês para $\mathrm{mm} / \mathrm{ano}$, têm-se uma taxa limite de 0,6154 mm/ano. Ao representar esta taxa de corrosão no gráfico da Sandvik, linha vermelha, a mesma ocorrerá com aproximadamente uma hora de sensitização. Tempo este similar ao utilizado pela DuPont para critério de avaliação da taxa de corrosão.

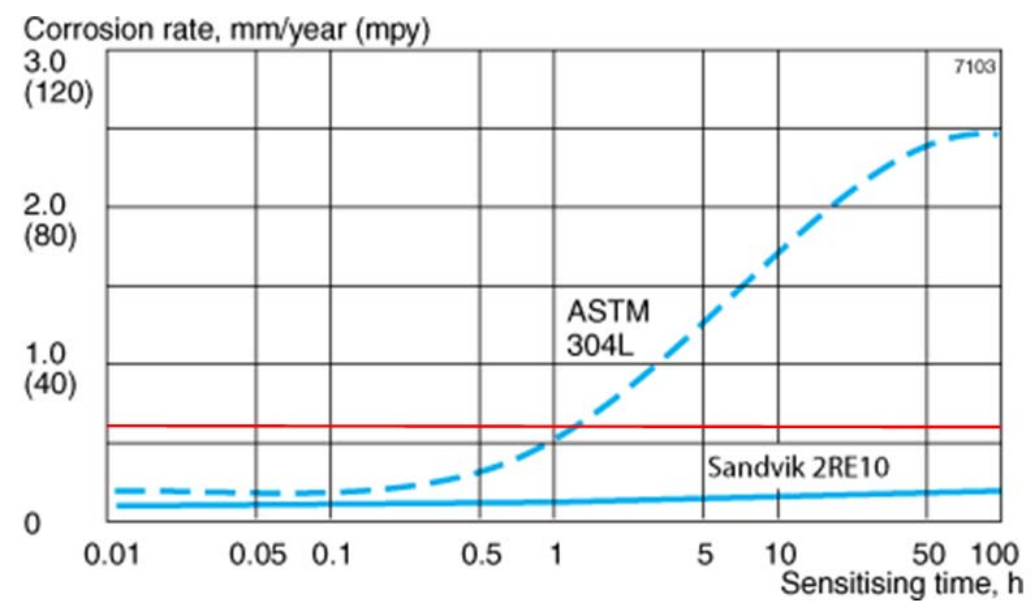

Figura 4. Taxas de corrosão obtidas através da Prática $C$ após sensitização a $675^{\circ} \mathrm{C}$. [5]

Para ambas as referências, as amostras 1 e 6 estariam rejeitadas a partir do primeiro ciclo, a amostra 3 do segundo ciclo e nenhuma das amostras seriam aprovadas para trabalho com permanência em temperaturas de sensitização por tempos maiores que 96 horas.

A Figura 5 exibe a superfície da amostra de número 1, que apresentou a maior taxa de corrosão após 144 horas de ensaio. A superfície foi bastante valetada, com arrancamento de grãos e ataque inclusive no interior dos grãos. Em todas as demais amostras o ataque à superfície foi em menor intensidade. 


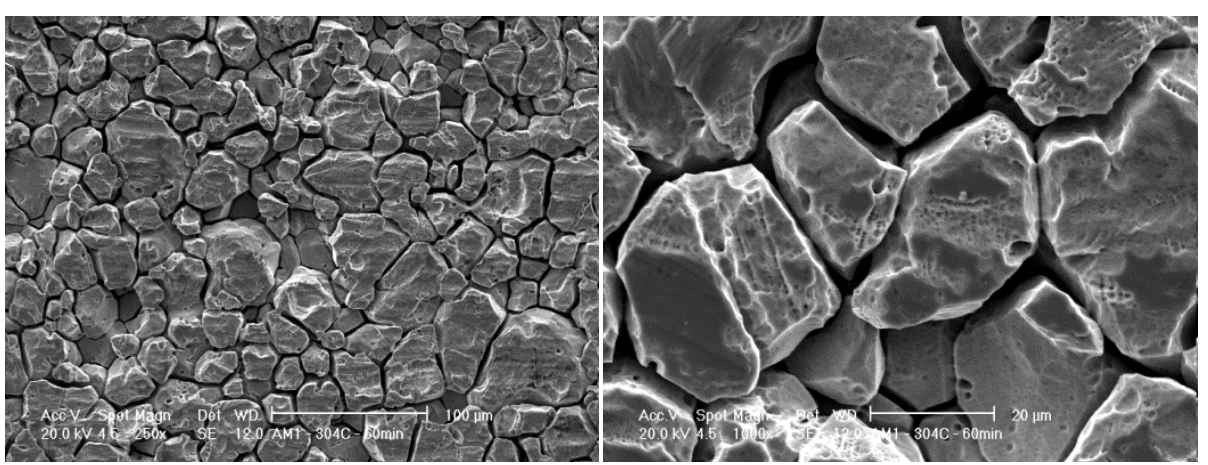

Figura 5. Superfície da amostra de número 1 do aço AISI $304 \mathrm{~L}$, sensitizado a $675^{\circ} \mathrm{C}$ por 60 minutos e imersa em solução nítrica em ebulição por 144 horas. Aumentos de, respectivamente, 250x e 1000x.

Deve-se ressaltar que esta norma não estabelece valor limite para que a taxa de corrosão seja considerada crítica. Assim como não determina o tempo e a temperatura em que deve ser realizado a sensitização prévia. Outro ponto delicado na análise dos resultados desta prática é que, pela condição altamente agressiva do meio, pode-se ter a ocorrência de outros tipos de corrosão. O que irá alterar o resultado da análise da perda de massa por corrosão intergranular. Em função dos pontos acima, não se recomenda o uso deste ensaio para a comprovação da tendência a sensitização.

\subsection{ASTM A262 - Prática E}

Após o ensaio nenhuma amostra sofreu qualquer tipo de fratura. As amostras foram analisadas macroscopicamente e nenhuma delas apresentou trincas ou micro trincas, evidenciando que as amostras não apresentaram corrosão intergranular. A análise dos resultados desse procedimento foi a mais robusta e direta, por se tratar de uma análise macroscópica e por não depender do julgamento da microestrutura pelo executor das análises.

\section{CONCLUSÃO}

A análise das amostras submetidas ao procedimento da norma ASTM A262 - Prática A, para liberação de material quanto à ausência de sensitização, pode gerar dúvidas na interpretação metalográfica do que é uma microestrutura valetada, mista ou degrau. Um rigoroso controle das variáveis envolvidas no ensaio (corrente, área a ser atacada) deve ser seguido.

O estudo de corrosão utilizando a metodologia da Prática $C$ fornece resultados que podem não ser representativos na ocorrência de outras formas de corrosão na amostra. Deve-se ressaltar também que esta norma não estabelece critérios claros da taxa de corrosão considerada crítica e da condição de tratamento térmico que deve ser realizado o teste. Em função dos pontos acima, não se recomenda o uso deste ensaio para a comprovação da tendência à sensitização. Como alternativa a Prática C da norma ASTM A262, em casos de dúvidas após a realização da Prática A, recomenda-se a utilizar a Prática $E$, de mais fácil realização e de resultado mais direto quanto ao critério aprovado ou não aprovado.

Após a realização dos três procedimentos, considera-se que a metodologia mais assertiva e confiável seja a Prática E, Ensaio de Strauss, e que as amostras de AISI 304L não apresentaram corrosão intergranular, pela não ruptura após dobramento. 


\section{Agradecimentos}

A Aperam South America, unidade de Timóteo em Minas Gerais.

\section{REFERÊNCIAS}

1 Padilha, A.F.; Guedes, L.C. Aços inoxidáveis austeníticos. São Paulo: Hemus Editora Limitada; 1994.

2 ASM Speciality Handbook: Stainless steels. Ohio: ASM International, Materials Park; 1994.

3 America Society for Testing and Materials. Standard practices for detecting susceptibility to Intergranular attack in austenitic stainless steels. (ASTM A262-02a). ASTM International: West Conshohocken; 2008.

4 Sedriks, John A. Corrosion of stainless steels. New York: Wiley Interscience Publication; 1979.

5 Sandvik. Handbook. Disponível em:<www.smt.sandvik.com>. Acesso em: 11 de Fev. 2014. 